\title{
Inativação de bactérias gram-positivas em superfícies através de luz ultravioleta pulsada
}

\author{
Fiamoncini, B.F.; Rowan, N; Garvey, M.; \\ Apresentador: Bruna de Franceschi Fiamoncini \\ Premiados - Menção Honrosa: Destaque acadêmico
}

\section{Resumo}

Introdução: Staphylococcus aureus é o causador mais comum de infecções nosocomiais em hospitais brasileiros. Clostridium difficile é patógeno reconhecido mundialmente como causador de diarreia nosocomial e colite associada a antibióticos. Staphylococcus aureus resistente à meticilina (MRSA) e E. faecium resistente à vancomicina (VRE) representam obstáculos ao sucesso terapêutico. A resistência destas bactérias a agentes de desinfecção comuns, como clorexidina, sugere que novos métodos de descontaminação precisam ser estabelecidos para prevenir infecções nosocomiais. A luz ultravioleta pulsada (PUV) é eficaz na descontaminação de superfícies de vários materiais. O método demonstrou-se superior à limpeza manual para descontaminação de MRSA em quartos de hospital. Este estudo avalia o potencial de um sistema de PUV para a inativação de VRE, MRSA e C. difficile nas formas planctônica e biofilme. Métodos: O sistema PUV utilizado consiste em uma máquina que emite pulsos de luz UV de largo espectro através de uma lâmpada de xênon. A inativação com PUV das espécies testadas conduziu-se nas formas planctônica e biofilme. Cultivou-se os biofilmes através do reator CDC de biofilme, em uso de meio de cultura apropriado, por 72 horas. Cupons de aço inoxidável e PVC foram escolhidas como superfícies para o crescimento dos biofilmes, pois são materiais utilizados em meio clínico. Realizou-se análise estatística para comparar os níveis de sensibilidade sob diferentes doses de tratamento. Resultados: Células de biofilme são mais resistentes do que planctônicas para todos os organismos tratados. A PUV inativou as espécies testadas com sucesso. Obteve-se níveis significantes $(\mathrm{p}<0,05)$ de inativação em PVC e aço inoxidável. VRE produziu biofilme mais populosamente denso em aço inoxidável, enquanto MRSA criou biofilme mais populosamente denso em PVC. Alcançou-se inativação máxima de 9,3 e 7,4 $\log 10$ em superfície para MRSA a VRE, respectivamente. Em suspensão, alcançou-se inativação de $9 \log 10$ para MRSA e 6,55 $\log 10$ para VRE. C. difficile mostrou-se a espécie mais resistente aos raios UV na forma planctônica. Conclusão: O sistema PUV utilizado levou à inativação de MRSA, VRE e C. difficile. Os resultados sugerem a PUV como método para a erradicação destes problemáticos microrganismos do meio clínico. Além disso, a elevada taxa de inativação de cepas planctônicas sugere que a inativação com PUV pode servir como medida preventiva ao crescimento de biofilme.

\section{Referência:}

Fiamoncini, B.F.; Rowan N , Garvey, M.;.;. Inativação de bactérias gram-positivas em superfícies através de luz ultravioleta pulsada. In: II Congresso Brasileiro de Medicina Hospitalar - II CBMH [= Blucher Medical Proceedings, vol.1, num.5] São Paulo: Editora Blucher, 2014. p.7

DOI 10.5151/medpro-II-cbmh-056 